\title{
Learning from the whirlpools of existence: Crises and transformative processes as complex and rhythmic phenomena
}

\author{
Michel Alhadeff-Jones \\ Teachers College, Columbia University, USA/Institut Sunkhronos, Suisse \\ (maj@sunkhronos.org)
}

\begin{abstract}
The aim of this paper is to problematize and enrich the use of the concept of crisis in adult education to theorize further its contribution to the study of transformative processes. This paper discusses first the implications inherent in the adoption of event-based and processual approaches to crises. It seeks then to nuance and problematize the ways in which the relationships between crisis, learning and (trans)formative processes are conceived in adult education, especially through transformative learning theory and biographical approaches. The reflection highlights the difficulty of capturing the fluidity of learning and (trans)formative dynamics. Inspired by Edgar Morin's paradigm of complexity and illustrated by examples taken from the COVID-19 pandemic, three principles are defined to help conceiving what structures, regulates and reorganizes such dynamics. The contribution concludes by emphasizing the importance of developing a critical awareness of the rhythms that shape educational processes.
\end{abstract}

Keywords: Adult education, crisis, transformation, complexity, rhythm, COVID-19

\section{Learning from the whirlpools of experience}

Every crisis leaves traces that appear both through the regressions and the advances that emerge from it. In many regards, when we refer to the lessons learned and the transformations associated with the experience of a crisis, we are referring to its most striking effects, what emerges from it. However, from an educational perspective, the

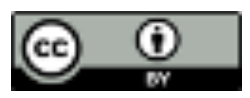


experience of a crisis cannot be reduced to the explicit marks it leaves. The outcome of a crisis depends indeed on all the activities deployed to contain, regulate, and transcend it, before, during and after the occurrence of a specific perturbation. These activities manifest themselves through processes that express the evolution of tensions (e.g., dilemmas, psychological distress, social conflicts) whose effects over time eventually lead to the emergence of specific transformations.

As the river carves its bed, the experience of a crisis leaves deep traces. If, retrospectively, the erosion caused by the continuous flow of water demonstrates the transforming power of a river, it does not, however, reveal the whirlpools that agitate it. It may be the same with the experience of a crisis. The resulting traces give an account of the significant changes in which it participates, whereas the everyday learning experiences that contribute to it tend to fade in the memories that we can keep of it. Their fluidity thus appears to be repressed in a form of "rhythmic unconscious" (AlhadeffJones, 2020). However, the recognition of these whirlpools of experience also carries significant learning opportunities. These swirls refer to our everyday experiences of change. They manifest the intrapsychic, interpersonal, and social dynamics that (trans)form individuals and collectives, day after day. More fundamentally, the study of these whirlpools may open up possibilities to interpret the ways in which forms of influence, power, and constraint unfold both, in crisis situations and in normal times, on a daily basis and over the long term (Alhadeff-Jones, 2017; Michon, 2005).

Beyond the metaphor, referring to the fluidity inherent to a crisis remains however problematic. It raises questions about the ways we interpret how people, collectives, and organizations experience or display ever-changing and inconsistent behaviours, fluctuations in the way they find and maintain themselves in equilibrium, and how variations affect the way they evolve throughout their existence. From an educational perspective, the opportunity provided by the current pandemic questions how to comprehend the (trans)formative effects of a crisis as they unfold, and how to study learning and transformational processes that seem to escape a sense of predictability, consistency and clarity. Between order and disorder, understanding the educational dimensions inherent in the experience of crises requires therefore the elaboration of a conceptual framework that embraces the complexity of such phenomena.

\section{Reconsidering the meanings of the concept of crisis in adult education}

The term "crisis" has been ubiquitous in everyday language far before the pandemic of COVID-19 started. Its recurrence is likely a marker of modernity (Béjin \& Morin, 1976; Kjaer \& Olsen, 2016; Koselleck \& Richter, 2006). As the French sociologist and philosopher Edgar Morin reminded us in 1976, there is no field that is not haunted by the idea of crisis. However, through its generalization, the term has also been emptied of its meaning:

\footnotetext{
Originally, Krisis meant decision: it is the decisive moment in the evolution of an uncertain process that allows for the diagnosis. Today, crisis means indecision. It is the moment when, at the same time as a disturbance occurs, uncertainties arise... The word is now used to name the unnamable; it refers to a double gap: a gap in our knowledge (at the very heart of the term crisis); a gap in the social reality itself where the "crisis" appears. (Morin, 1976, p.149, my translation).
}

Thus, for Morin, the key problem is to determine 'how to clarify [éclairer] the concept of crisis? [and] How to make it enlightening [éclairant]?' (Ibid.) In educational sciences, the 
use of the concept of crisis presents a threefold interest. First, it raises questions about our conceptions of change and the ways we define the nature of the subjects and objects that are altered by it. Accordingly, the first part of this paper is going to discuss the relevance and the implications inherent to the adoption of a processual approach to study crises in adult education. Referring to the concept of crisis also leads to questioning how we interpret the discontinuities that disrupt the life course and the relationships they have with ongoing learning and (trans)formative processes. The second part of this paper will thus present a succinct overview of existing theories in adult education to position their current contributions and limitations when it comes to interpret the relationships between crises, learning and transformation. Finally, the experience of a crisis also reveals the fluidity of learning and (trans)formative dynamics, as they unfold over time. Studying the relations between crises and educational processes raises therefore questions regarding the principles based on which we can interpret such phenomena. The third part of this article is going to develop more extensively this problematic by addressing three questions: How to conceive what structures learning and (trans)formative processes, taking into consideration both the fluidity and the rigidity they may display in a context of crisis? How to conceive the ways such processes unfold through time, considering both the fluctuations and steadiness they may exhibit? How to envision the movement through which learning and (trans)formative processes evolve, considering both the constancy and the variability that may characterize their development?

\section{Event-based and processual approaches to crisis}

Crisis phenomena can be considered in two distinct ways (Roux-Dufort, 2000, p.18). On the one hand, the crisis can be considered as an event. In doing so, it tends to be confused with the incident that triggered it, which is considered to be brutal, punctual, surprising, unpredictable and improbable. Conceived in this way, the crisis is characterized by the rapidity of its development, the compression of the time for decision-making and the confusion of the circumstances associated with it. An event-based approach to crises therefore tends to favour a study of the facts considered a posteriori, favouring a reactive posture, rather than an approach based on anticipation and prevention (ibid.) On the other hand, the crisis can also be understood as a process. From this point of view, it is envisioned through a progression in its intensity and visibility, allowing for different stages (e.g., precursory signs, triggering, amplification, resolution). As Roux-Dufort (2000, p.18, my translation) points out, this approach allows:

... the possibility of predicting the crisis or tracing its genealogy and the dynamics of its occurrence. In this sense, it moves away from the mere analysis of symptoms and opens up broader avenues of investigation for learning about crises.

A processual approach thus suggests that a crisis should be conceived as the product of cumulative and potentially detectable dysfunctions or tensions, the dynamics of which may suddenly appear out of control. Similarly, it refers to the complexity of the systems within which the crisis unfolds, insofar as the large number of interacting elements and the multitude of their interrelationships contribute to making the emergence of a crisis inevitable, even if it remains unlikely and unpredictable. A processual approach to crises thus leads to a systemic, complexivist and multidimensional conception. It leads to focus our attention prior to the triggering event, on the conditions that favoured its emergence, while at the same time questioning the dynamics that allowed it to unfold (Roux-Dufort, 
2000 , p.22). In so doing, it allows the experience of the crisis to be situated in a timeframe that also makes it possible to contemplate the unfolding of learning and (trans)formative processes.

Adopting such a conception of the crisis is not self-evident, however. The opposition between an event-based conception and a processual conception of change may appear as a simple theoretical alternative. However, as Jullien (2011) develops it in his reflection on "silent transformations", this duality in fact refers to a more fundamental ontological posture that determines the way in which we conceive not only change, but also and above all the nature of the entities whose transformations we study (e.g., the knowledge, the learning subject, the community). Where an event-based approach assumes the existence of stable entities that would be disrupted by the events that affect them, a processual approach suggests considering them from the point of view of the ongoing dynamics that animate them (Rescher, 2000). A processual approach to adult education thus emphasizes the study of the active and changing aspects that make up educational phenomena, rather than what constitutes their substance. From this perspective, the learning subjects, knowledge, and skills, as well as the organizational arrangements and frameworks involved in education, should be conceived primarily in terms of the (ordered) processes and (disordered) dynamics from which they emerge and in which they participate, rather than in terms of the forms of equilibrium and stability that would characterize them in the course of their evolution (Alhadeff-Jones, 2018).

\section{Crisis, learning and (trans)formative processes}

A crisis has at least three properties that make it particularly interesting from the point of view of learning and (trans)formation: it refers to a process that manifests itself in stages, before and after the triggering event; it brings together different systems, actors and issues that are sometimes heterogeneous from one another; and finally, it invalidates traditional response patterns by confronting the actors with the limits of their ways of perceiving, interpreting and evaluating the events they face (Roux-Dufort, 2000, p.45). To the extent that it escapes all regularity and does not fit into the mould shaped by previous events, the experience of a crisis positions the individuals and communities that face it in a kind of vacuum that can be lived as a threat and/or an opportunity. The crisis thus confronts individuals and institutions with the need to rediscover or restore meaning to the actions undertaken. To the extent that the crisis confronts a collapse of reference points, it proves to be liberating and favours the generation of ideas that in normal times would be considered unacceptable, but which under the impact of the disruption, take on their full meaning (Roux-Dufort, 2000, p. 46).

The experience of a crisis can lead to two outcomes, one regressive, the other progressive (Morin, 1976, p. 160-161). On the one hand, the crisis involves a potential for regression, which is characterized by the loss of complexity and flexibility of the system: the richest qualities and the freedoms acquired disappear, while the most primitive or rigid structures are consolidated. From a learning perspective, the crisis can be experienced as so exceptional that it does not appear as an opportunity for change. The stupefaction it provokes constitutes such a threat that it prevents the development of the lucidity necessary to distance oneself from it in order to recognize new solutions. Similarly, the rarity of the situation and the uniqueness of its manifestations give the feeling that it is not possible to draw on past experience to deal with it. These uncertainties activate individual and collective defence mechanisms that are too important to allow new learning to emerge (Barus-Michel, Giust-Desprairies, \& Ridel, 1996; Roux-Dufort, 
2000). On the other hand, the crisis can also lead to progress that manifests itself through the acquisition of new qualities or properties that contribute to the complexification of the system (Morin, 1976, p. 161). From this point of view, the experience of crisis mobilizes processes of reconfiguration that lead to more or less profound disorganizations and reorganizations that participate in a transformative, even evolutionary process. Thus, crises represent both learning opportunities likely to lead to (trans)formative effects, while at the same time inducing constraints that considerably reduce their (trans)formative potential. In order to understand and nuance the relationship between crisis experiences, learning processes and their transformative potential, it seems relevant at this stage to distinguish three levels of learning, as highlighted in several change and educational theories. Once this distinction is established, two referentials will be discussed in a more specific way (transformative learning theory and biographical approaches in adult education), to further problematize the ways in which the relationship between crises and transformational processes is accounted for in educational theory.

\section{Three levels of learning}

At a first level, the experience of the crisis refers to behavioural changes that occur progressively and contribute to modifying the routines and ways of functioning within a system, according to the experience acquired. "First-order learning" (Bateson, 1973), "single-loop learning" (Argyris \& Schön, 1978), or "instrumental learning" (Mezirow, 1991), refer to relatively superficial changes aimed at finding solutions to problems encountered, while remaining in conformity with pre-established goals. In a crisis context, it is thus a matter of learning to regulate some of its effects, without questioning the norms and values that determine the context of action. This type of learning thus makes it possible to maintain the status quo while adjusting to changes in the environment. As Roux-Dufort (2000, p.57) points out, while it allows certain short-term perturbations to be regulated, this type of learning has a number of limitations. By reducing the experience of a crisis to an exceptional event whose only purpose is to manage its negative effects, the learning undertaken does not allow for the consideration of new frameworks of reflection, in order to respond to the imbalances and tensions experienced. By not questioning the conditions that led to the emergence of the crisis, this type of learning cannot resolve the discomfort and sense of collapse associated with sudden change and the deployment of tensions accumulated over time.

A second level of learning occurs when individuals or groups change their frames of reference or the assumptions from which they interpret their experiences. This type of learning refers rather to a discontinuity based on the questioning of the assumptions and hypotheses that have guided action until then. This is referred to as "second-order learning" (Bateson, 1973), "double-loop learning" (Argyris \& Schön, 1978), or "communicational learning" (Mezirow, 1991), as it relates to the meanings of the actions undertaken. From this point of view, the crisis, the antagonisms and the dilemmas it brings with it, raise consciousness and provoke a process of elaboration that has the effect of making explicit the "meaning perspectives" (ibid.) from which individuals and institutions define the norms, values and basic principles that guide their actions. For Roux-Dufort (2000, pp.57-58), this type of learning expresses the irreversible process of questioning initiated by the crisis. In the long term, however, it can prove problematic insofar as it forces actors to reposition themselves, in a reactive manner, under the pressure of a critical situation, and not necessarily by virtue of a vision or a desire for change. 
Finally, a third level of learning can be distinguished. It involves the ability to distance oneself from the consciousness-raising process described above. Referred to as "thirdorder learning" (Bateson, 1973), "triple-loop learning" (Tosey, Visser \& Saunders, 2011) or "emancipatory learning" (Mezirow, 1991), it is based on the understanding and transformation of the assumptions from which we make sense of our experience. Through an in-depth inquiry, one actively seeks to question the frames of reference and paradigms that limit the actions undertaken and the ways of thinking and feeling about them. At this level, the effects of a crisis have repercussions on identity and on the way, one defines the meaning of one's own existence. This type of learning refers to a different understanding of the crisis which lies in what it reveals. At the individual level, it can, for example, be based on an in-depth analysis of the biographical processes (Dominicé, 2000) that account for the responses produced in a crisis situation, and the interpretative frameworks that they reveal (Mezirow, 1991). This type of learning requires an awareness of the dialectical and chaotic nature of crisis phenomena. It involves, for instance, moving beyond binary interpretative frameworks (e.g., positive/negative, external/internal, production/destruction) and engaging in an active search for meaning. This is particularly difficult insofar as it confronts individuals to tensions generated by the awareness of the limits, obstacles and sacrifices that must be made in order to overcome one's own assumptions and to recognize the inevitability of the doubt and anxiety from which the learning process must draw (Roux-Dufort, 2000, p.58).

\section{Crises and adulthood: Contributions and limits of transformation theories}

When it comes to conceiving the articulation between different types of learning and understanding the transformative role inherent in episodes of crisis experienced throughout existence, two types of contribution regularly appear in the adult education literature: those that refer to transformative learning theory and those that are inscribed in the tradition of life histories and biographical research. These two frames of reference have contributed significantly to the development of research on transformative processes in adulthood. Nevertheless, they present certain limitations that need to be addressed to better understand the complexity of the relationship between crisis, learning and (trans)formation.

By distinguishing different types of learning (instrumental, communicational and emancipatory) involved in a transformational journey, by specifying some of the conditions required for transformation to occur (e.g., dialogue, critical reflection), and by modelling the phases constituting a transformational process, transformative learning theory (Mezirow, 1991) offers a particularly appropriate conceptual framework for understanding the relationships between disruptive experiences, crises, and transformative processes (Alhadeff-Jones \& Kokkos, 2011). However, this theory suffers from several limitations. First, it does not explicitly refer to the concept of crisis, favouring instead the notion of "disorienting dilemma". In so doing, it does not fully account for the extreme implications that characterize sometimes the events that mark out existence, and in particular the intense emotional, social, and political dimensions revealed by crises. Moreover, insofar as it locates the origin of a transformative process in the discontinuity introduced by the experience of a dilemma, this theory does not problematize the dynamics that precede the appearance of a disturbing event that may determine the responses it triggers. Moreover, the theory of transformative learning lacks a conceptual apparatus for describing the temporal complexity in which the phenomena of crisis and (trans)formation are embedded (Alhadeff-Jones, 2017, 2019a). The 
understanding of transformation processes is thus based on a divide between, on the one hand, an event-based approach to change, emphasizing lived discontinuities, and, on the other hand, the recognition of the role played by processes inscribed in a continuum (e.g., dialogue, critical reflection). The whole process is apprehended through a relatively ordered developmental sequence that supposedly transcends a given context (Nohl, 2015), but does not explain according to which principles the ebbs and flows between stages of transformation may evolve through time.

Contributions from the field of life histories and biographical research offer an alternative frame of reference for considering the relationships between crisis, transformative processes, and adulthood. Taking personal history into account appears to be a determining factor in understanding phenomena of crisis and transition in adulthood. Boutinet (1998) thus suggests integrating the crisis phenomenon (whether it is of internal or external origin for the subject) into a broader process of transition, envisioned as '[a]n intermediary area of experiences, full of instability and trial and error' (Boutinet, 1998, p.58, my translation). The crisis thus refers to a transitional process of passage, which depends on the age range in which it is lived (e.g., young adulthood, mid-life, retirement), the type of experience to which it refers (e.g., professional, relational, etc.), its duration and its rhythm, and the means used to manage it. It thus implies:

... a mourning to be lived which assimilates it to an experience of liminality: a threshold is to be crossed, an initiation is in the process of taking place which makes it possible to give up a certain former state to allow the accession to a new psychological status by a transition to be managed towards new attachments... (Boutinet, 1998, p.59, my translation).

The recourse to life histories thus constitutes a precious means to describe and interpret the role played by the experiences of crisis as they relate to phenomena of transition and transformation, throughout the existence. By making explicit the historical framework on which transformation may unfold (e.g., Alheit, Bron-Wojciechowska, Brugger, \& Dominicé, 1995; Delory-Momberger, 2003; Dominicé, 2000; Pineau, 2000; West, Alheit, Andersen, \& Merrill, 2007), biographical research undertaken in the field of adult education involves narrative processes that privilege the enunciation of experiences lived as singular or critical: epiphanies, ruptures, crises, bifurcations, transitions, etc. (Baudouin, 2014; Galvani, 2019; Lesourd, 2009). However, this type of approach has its own limitations. For example, by placing the emphasis on events, intense moments, or ordeals experienced, the work done using life narratives tends to neglect the role played by the recurring experience of everyday phenomena of low amplitude (e.g., microaggressions). The plot that organizes life narratives tends to ignore or minimize the description of routines, habits and the phenomena of accumulation or saturation that constitute the banality of everyday life (Alhadeff-Jones, 2020). Finally, by emphasizing the discontinuities of existence and the unique character of each successive period of life (e.g., childhood, adolescence, entry into adulthood), autobiographical writings do not always make it possible to enunciate in a systematic way what tends to be repeated in the transitions lived and in the recurring crises experienced at the different stages of one's existence.

\section{The fluidity of (trans)formative processes revealed in a crisis}

The experience of a crisis is characterized by a progression of disorders, instabilities and contingencies that increase uncertainties and make its effects unpredictable (Morin, 1976, p.156). In this sense, one of the fundamental characteristics of crises lies in the fact that 
they reveal the fluidity of the phenomena that constitute them. From an educational point of view, this feature is crucial to recognize, insofar as it refers to the uncertain, unstable, changing, and hard to grasp dimension that characterizes the various states experienced, as well as the flexibility and plasticity of the learning and (trans)formative processes that unfold over time. The experience of a crisis thus highlights the uncertainties, ambivalences, ambiguities, but also the tensions and conflicts which, in a complementary and contradictory way, stimulate and hinder the learning processes experienced, both individually and collectively. It reveals a fluidity that can be found at all levels: when seeking solutions to re-establish a form of normality, when questioning the meanings, norms and values that guide our actions, or when challenging the foundations that ground "meaning perspectives" (Mezirow, 1991), in order to engage in more fundamental transformations. Between the relative superficiality of learning that aims to establish a process of normalization and the emergence of deeper processes of change that can be experienced as regenerative, the effects of a crisis reveal the fluctuations and oscillations that characterize the dynamics of (trans)formation.

Envisioning the experience of a crisis through the fluidity it reveals may constitute a desirable aim from an educational perspective. For the subjects who experience them, it remains however often problematic. Being confronted to instability and inconsistency may lead people to experience feelings of disbelief, insecurity, anxiety, fear, and even violence and brutality, that may be perceived - consciously or not - as threatening for the integrity of the self, or for the cohesion of the collective (Barus-Michel, Giust-Desprairies \& Ridel, 1996, p.36). As suggested by Kaës (1979), what seems crucial to overcome and learn from a crisis remains the capacity to create a symbolic space, and use discourses and exchanges as means to contain, elaborate, represent, and conceive the tensions and dynamics involved. For the researcher and the practitioner, it is not straightforward neither to be dealing with people coping with a crisis, or recollecting memories associated to it. Beyond the subjective implications it may involve (Barus-Michel, Giust-Desprairies \& Ridel, 1996), it raises theoretical questions about the conceptual bases on which to describe and interpret the "flow" that is constitutive of the experience of a crisis, as well as the "fluxes" through which its tensions unfold. Many contributions in human sciences may provide frameworks to proceed (e.g., Marxian or Freudian theories). In order to embrace the complexity of crises and the multiple facets involved in individual and collective transformations, the reflection conducted in the following sections refers specifically to Morin's (1976) theory of crises; a contribution that is embedded in his paradigm of complexity (Morin, 2008) and that provides us with transdisciplinary principles highlighting and formalizing the complex dynamics inherent to crises and their effects, independently of the theories used to interpret their specific origins or manifestations.

\section{Conceiving the complexity of learning and (trans)formative processes}

According to Morin's (1976) contribution, in order to conceive of crisis, it is first necessary to go beyond the notions of disturbance, ordeal, and rupture of equilibrium, and to consider society and its constituents as systems capable of having crises. To do this, Morin favours three principles of analysis inspired by complexity theories: the first is systemic, the second cybernetic, the third negentropic. The following sections explore successively these three levels of analysis, seeking to establish some of the issues they raise from the perspective of learning and (trans)formation, and illustrating them with examples drawn from the context of the COVID-19 pandemic. 


\section{Systemic approach and antagonisms}

As Morin reminds us, the idea of system refers to a whole organized by the interrelation of its constituents:

For there to be a system, there must be the preservation of difference, that is, the preservation of forces safeguarding at least something fundamental in the originality of the elements or objects or interrelations, thus the preservation, counterbalanced, neutralized or virtuality, of forces of exclusion, dissociation, repulsion. (Morin, 1976, p.150)

In this perspective, any organized system (e.g., a person, a collective, an institution, a society), rests on equilibriums that involve both complementarities and antagonistic forces. Two postulates are thus proposed: (1) The complex unity of the system both creates and represses antagonisms; (2) systemic complementarities are inseparable from antagonisms. And Morin specifies: 'These antagonisms remain either virtual, or more or less controlled, or even ... more or less controlling. They erupt when there is a crisis, and they make a crisis when they are in eruption.' (Morin, 1976, p.151).

\section{The crisis as a revealing of the antagonisms that structure learning and (trans)formative processes}

Analysing the complementarities and antagonisms revealed by the experience of a crisis, such as the COVID-19 pandemic, makes it possible to apprehend and grasp the polarities, oppositions, contradictions, paradoxes, tensions, conflicts, but also the ambivalences, hesitations, and dilemmas through which processes of change, learning and (trans)formation unfold. At the behavioural and instrumental level, the experience of the pandemic confronts people on a daily basis with decisions that are made in the midst of doubt and that manifest hesitations and tensions that evolve as they acquire new knowledge. Having to choose whether to wear a mask, under what conditions to send one's children to school, or whether to trust official policies: these are all situations to be resolved on a daily basis that involve decision-making and learning about oneself, others, and the world. When we consider the frames of reference mobilized to make sense of the situations we experience, we are also exposed to tensions that challenge the norms, values, principles, and interests that guide our actions. This is the case, for example, when it comes to accommodating the education of one's children and maintaining one's professional activities at home, or at a macro level, when a government has to balance the contradictory requirements of economic recovery and sanitary measures. If these questions are discussed and reflected upon, they can lead to positions that open the way to second-order learning that can affect the meaning we give to our actions. The experience of the crisis also brings to the fore deeper ambivalences and tensions, particularly concerning the position to adopt regarding the long-term effects of the crisis and the means used to deal with it. On a personal level, dilemmas may arise between the need to reorganize one's daily life and the desire to reorient one's personal or professional life. On a collective level, the crisis also reveals oppositions and ambivalences between two postures: one that favours adjusting the way existing systems operate (health, work, commerce, transportation, etc.) and the other that aspires to more radical transformations. Thus, third-order learning appears virtually in a tension between the search for balance and normalization on the one hand, and the opportunity for openness and transformation on the other. 


\section{The fluidity of learning and the patterns that organize it over time}

The identification of antagonisms and tensions in crisis situations leads us to consider how learning and (trans)formative processes evolve through fluctuations between states, behaviours, beliefs, or postures. Adopting Morin's systemic view suggests that such phenomena are neither totally ordered nor fully disordered. Rather, the presence of complementarities and antagonisms reveals differentiated sets of tensions that organize people's experiences. Such patterns may for instance refer to antagonistic embodied experiences (e.g., immobility vs mobility; healthy vs unhealthy), conflicting psychological states or dispositions (e.g., well-being vs suffering, high vs low selfconfidence, trust vs scepticism), contradictory ideological values (e.g., liberal vs conservative), or differentiated social status (e.g., single vs in a relation, autonomous vs dependant, expert vs novice, employed vs unemployed). The adoption of Morin's systemic perspective suggests one to explore which patterns are revealed by people's experience of a crisis, and how people relate to them over time. From an educational perspective, the fluctuation that comes with the alternation between different states may be critical to explore and question. It opens the possibility to envision the fluidity of the life course through the recurring dialogical tensions that are constitutive of the fabric of one's existence (Alhadeff-Jones, 2017, 2020, 2021b; Bachelard, 1950). Beyond the crisis that may reveal them, the recurrence of such dualities in one's life may appear as a marker that shapes learning processes and the singular flow of one's own development. Thus, the recognition and the description of such patterns may appear as critical. They may lead people to develop the capacity to interpret and eventually influence how they relate to the meaningful tensions and antagonisms that organize the course of their personal and professional lives, beyond specific perturbations.

\section{Cybernetic approach and regulatory mechanisms}

To explain for instance how a thermostat maintains the temperature of a room stable, a cybernetic view focuses on the regulating processes (positive or negative feedback) that allow a system to be maintained in equilibrium (homeostasis) based on the antagonisms at play (e.g., heat vs cold). As Morin (1976, p.151, my translation) states:

When we consider systems of cybernetic complexity ... the machine, the cell, the society, that is, with regulating feedbacks, we find that the organization itself elicits and uses antagonistic behaviours and effects from certain constituents. This means that there is also organizational antagonism.

The regulation of a system is therefore based on the antagonistic action of one or more elements on other elements of the system, as soon as these elements vary beyond a zone of tolerance, threatening the stability, the homeostasis, or even the integrity of the system: 'Thus antagonism does not only bring about the dislocation of the system, it can also contribute to its stability and regularity.' (Morin, 1976, p.152, my translation).

\section{The crisis as a revealing of the mechanisms that regulate learning and (trans)formative processes}

In the case of the COVID-19 pandemic, regulatory processes involving negative (inhibition) or positive (reinforcement) feedbacks are omnipresent both, at the individual level (e.g., rituals or defence mechanisms inhibiting the anxiety felt) and at the level of 
the collective, including social regulatory strategies (e.g., minimizing risks of exposure, increasing treatment capacities), political measures (e.g., reducing expressions of dissent, strengthening policies), or economic policies (e.g., saving resources, providing financial support or stimulus). The ways in which these regulatory mechanisms unfold reveal how learning processes evolve through cycles. First, the efforts made individually and collectively to cope with the perturbations caused by the crisis rely on schemes that belong to the repositories of known responses (e.g., denial, confinement) and are inscribed in specific antagonisms (e.g., confronting vs avoiding a threat, closure vs opening). Initially applied indiscriminately, they are progressively reproduced and adjusted, based on resources available, knowledge acquired and experimentations. From a behavioural perspective for instance, preventions strategies have eventually been developed through the experimentation, ritualization, and appropriation of simple gestures (e.g., wearing a mask, washing hands, keeping distance, opening windows, respecting quarantine). To be implemented during periods long enough to be effective, such measures have also required people to assimilate, from a cognitive point of view, the counter-intuitive and non-linear feature that characterizes the periodic progression of the contagion process (i.e., latency period between the moment of contamination and the appearance of symptoms, logarithmic increase of cases during this same period). Since the beginning of the pandemic, the repeated attempts to control the peaks of the contagion have led people to perceive successive "waves" of contamination. Both practically and symbolically, each new wave has proved to be a potential source of second-order learning, related to the meaning of this crisis in our lives and the questions it raises. If the first wave revealed in Europe, for example, the lack of anticipation of policies, the weaknesses of health systems and supply chains, and the importance of certain professions located on the "front line", the following waves have led to questioning the tolerance of populations with regard to the measures of constraint that have been imposed on them (in relation to their capacity to subsist, their family, work, consumption and travel habits, etc.), opening the way to a re-examination of the meanings attributed for instance to our ways of living. As the awareness of the successive attempts to regulate the crisis grows, the experience of the cycles of the pandemic questions, more fundamentally, how people learn to regulate the balance between preserving habits, knowledge, and beliefs, and initiating new ways of perceiving and giving meaning to their recurring experiences. At the epistemic level, it challenges for instance the way in which institutions regulate, on the one hand, the search for technical solutions (e.g., prevention tools, vaccines, treatments) and, on the other hand, the responses to be provided on a human level (e.g., in terms of meanings, norms and values).

\section{Learning processes and the regulations around which they are organized in time}

By emphasizing the role played by regulatory mechanisms, the cybernetic point of view leads to an examination of the nature of the fluctuations through which individuals and collectives maintain themselves in equilibrium or fail to do so. Regulatory processes rely on antagonisms that display specific patterns. These define the individual and collective strategies implemented to cope with the uncertainty of the crisis. Their evolution reveals a second kind of fluctuation that determines how learning and (trans)formative processes unfold through time. Such fluctuations appear through the repetition of loops, cycles, returns, or alternances through which the crisis is experienced. Considering the repetitive nature of these processes suggests - among other - that we pay attention to the features that characterize their recurrence before, during and after the crisis. From an educational 
perspective, studying the phenomena of repetition associated with a crisis is heuristic. First, it leads to question how the crisis relates to previous learning experiences and, more specifically, to existing modalities of regulation that may be re-enacted to cope with it (e.g., feelings, thoughts, behaviours, strategies, that may be reproduced, in a functional or dysfunctional way) (Barus-Michel, Giust-Desprairies, \& Ridel, 1996). Second, it brings us to pay attention to the modalities of regulation themselves and the way they influence the possibilities to learn from them. For instance, each person may experience the reproduction of everyday routines involved in the management of a crisis at a particular pace. For those in the "front lines" (e.g., health workers), the experience of the crisis may seem like an overwhelming shock or an exhausting race, letting limited room for processing one's experience to avoid its traumatic impact. For those experiencing it from the far, it may seem like a slow-motion process letting more time for self-reflection and dialogue. Such heterogeneous experiences regarding the possibility to regulate the tensions inherent to the crisis, and the repetitive activities it involves, also raise challenges in order to make the experience educationally beneficial for all. Thus, it raises additional questions: How the pace of the crisis is experienced (e.g., feeling of urgency versus boredom)? What are the disparities observed in the ways people relate to the regulation of their activities (e.g., availability or lack of resources to cope with regulatory measures)? Who has the power to influence the frequency or the tempo through which regulatory measures are implemented? How much it can be regulated, and how does it impact the meanings people associate with the overall situation?

\section{Negentropic approach, reorganization processes and emergences}

Like a fire turns wood into ashes, entropy refers to the natural tendency of an organized system to evolve irreversibly towards dispersion and disorder. In the reverse way, the negentropic level of analysis refers, in Morin's thinking (1976), to the study of the conditions required for a system to be able to reorganize itself continuously, or even to develop its complexity over time. In this perspective, the antagonisms present within a system (e.g., organism, family, institution) allow for the regulation of its processes (cybernetic principle), while at the same time carrying the risk of its disintegration, to the extent that the more they unfold, the more they contribute to the dispersion of the system's elements (e.g., radicalization). Morin thus reminds us that any organization maintains itself either by remaining immobile (fixed and static system), or by mobilizing energy that makes it possible to compensate for and control the forces of opposition and dissociation (antagonisms) that cause the system to tend towards dispersion. The negentropic analysis therefore concerns the modalities of transformation and evolution of an organized system, as well as the resources available to sustain it over time, and to inscribe it in a history that fluctuates between regression and reorganization. From a negentropic point of view, two features seem particularly critical to consider: the change of state that takes place at the crossing of a specific threshold (liminality) and the irreversible nature of such an emergence.

\section{The crisis as a revealing of emergences that reorganize learning and (trans)formative processes}

With regard to the evolution of the COVID-19 pandemic, a negentropic reading of the crisis questions the irreversibility of both its harmful and destructive consequences, and its (re)generative and constructive effects. Accordingly, phenomena of regression may 
appear as consequences of regulatory processes that favour the accumulation of deleterious factors (e.g., vulnerability, stress, isolation, inactivity, fatigue, poverty, insecurity, scepticism, inequalities) that may lead to breaking points. Conversely, progress may appear when regulatory processes participate in phenomena of concentration, accumulation, or regrouping (e.g., emotional, intellectual, social, financial resources) that facilitate the (re)organization and the emergence of new configurations of feelings, thoughts, actions, or interactions. Such experiences involve learning of different magnitudes (e.g., first, second or third-order learning). On an individual level, they appear for instance through changes and realizations caused by the experience of an acute or chronic illness, by the loss of a loved one, of a job, or by the confrontation with an unexpected situation of psychological, social and/or economic vulnerability. On a collective level, such emergences appear when realizing the significant failures or successes demonstrated by institutions in their attempt to control the effects of the pandemic (e.g., confinement and restriction of mobility, prolonged closure of schools, generalization of home-schooling and remote work, halting of air traffic, development of new vaccine technologies). The liminality of these experiences appears through their uniqueness and the ways they may be experienced as "first times". Such phenomena trigger the emergence of new ways of thinking, feeling, and acting to cope with them. These experiences can be observed or lived as signs of regressions, but they can also be interpreted as opportunities, insofar as they reveal openings to transform the existing order of things and benefit from enough resources to proceed. The COVID-19 pandemic is thus characterized by new thresholds that redefine among others : everyday behaviours (e.g., norms of distancing related to social interactions, time spent at home, tolerance to news lower or higher levels of workload); the understanding of the severity of the situation (e.g., epidemiological criteria defining the extent of the pandemic); or the transformations implemented in order to cope with it (e.g., change of professional status, family reconfiguration, exceptional allocation of resources, new legislative framework, technological advances). As the crisis progresses - or recedes - it thus reveals traces whose recognition, formalization and normalization reflect its irreversible and negentropic character.

\section{The reorganization and reconfigurations of learning processes}

A negentropic reading of the crisis approaches it from the point of view of (re)organization processes and the irreversibility of the history in which it is embedded. Thus, the cumulative effects associated with the reproduction of experiences involving antagonisms, tensions and the way they are (or fail to be) regulated, may contribute as much to threatening the integrity of the system (e.g., due to the depletion of resources, the radicalization of implemented measures, or their rigidity) as to allowing the emergence of new properties contributing to its renewal (e.g., by accelerating awareness, the diffusion of information, exchanges or collaborations). From an educational perspective, these phenomena participate in the reorganization of ways of thinking, feeling, acting, or collaborating, at the individual and collective levels. As the crisis unfolds, these reconfigurations become conscious through moments that may be interpreted as thresholds and that determine how people experience the irreversibility of the changes taking place. Negentropic processes thus refer to a third kind of fluctuation that characterizes learning and (trans)formative processes. Through the reconfigurations they produce, they reorganize and eventually regenerate the patterns and the repetitive dimensions through which learning and (trans)formative processes evolve, in the 
everyday life and throughout the lifespan. In adult education theory, such phenomena have been conceived mainly as third-order changes: transformative learning (Mezirow, 1991), kairos (Galvani, 2019), ordeal (Baudouin, 2014) or epiphany (Lesourd, 2009), for instance. To fully comprehend their discontinuous and irreversible features, it seems necessary to pay attention to the successive variations that build-up and eventually lead to the threshold of a transformation. Whether abruptly or incrementally, the experience of a crisis is characterized by specific effects of saturation that influence the ways people feel, think, act, or interact with each other. They may concern the environment (e.g., amount of $\mathrm{CO}_{2}$ released in the atmosphere), physiological processes (e.g., tiredness), psychological mechanisms (e.g., attention) or social phenomena (e.g., inequalities). From an educational perspective, paying attention to experiences of saturation and reconfiguration raises questions about the ways people and collectives learn to perceive and interpret, not only major disruptions, but also incremental changes whose manifestations are not obvious in normal times. It also questions the way people learn to sustain an awareness of such changes, despite weak signals or mechanisms of habituation.

\section{Studying and accompanying the flow of (trans)formative processes}

The position adopted in this paper goes beyond an event-based reading of crises and (trans)formative processes to explore more systematically the ongoing flows of activity (e.g., ways of feeling, thinking, acting, or interacting) that unfold in everyday life, before and after periods of disturbance. It should contribute to reinforce a scientific and social imaginary that envisions moments of rupture and crisis as "transitional" experiences (Kaës, 1979) that belong to the course of any adult life (Boutinet, 1998) and that are characterized by fluctuating states that need to be represented, understood, anticipated, contained, and accompanied. Inspired by Morin's contribution, the three principles proposed to study crisis phenomena lead to a conception of the complexity of learning and (trans)formative processes based on how they are structured (complementarities and antagonisms), how they are regulated (inhibition and reinforcement mechanisms), and how they are reorganized (liminality and emergences). Based on such principles, researchers, educators and learners may reflect on the experience of a crisis - and more broadly on any (trans)formative processes - as they unfold, by exploring more systematically: (a) the recurring tensions (embodied, psychological, social, ideological, etc.) that shape people, collectives, and organizations' activities, the polarities and the patterns they manifest, and the preponderance of specific forms of antagonisms organizing successive periods of their everyday life and existence; (b) the modalities of regulation implemented to moderate or reinforce such tensions through time, the resources they require, and the nature of the loops, cycles or alternances through which regulatory measures and actions are repeated or reproduced (their frequency, their pace, etc.); (c) the incremental variations or the weak signals, whose effects of saturation may eventually lead to the emergence of thresholds that determine more significant and visible reconfigurations in people, collectives and organizations' development.

\section{Toward a rhythmic theory of crisis and transformation}

Referring to Morin's contribution provides us with core principles to explore further the relationships between crises, learning and (trans)formations. Doing so, it provides theoretical grounds to reconsider what Alheit (1992, cited in West, Alheit, Andersen, \& 
Merrill, 2007, p.66) refers to as "biographicity", that is the ability to reconfigure the meaning of one's lifeworld in such a way that self-reflexive activities begin to shape the way one relates to a given social context. What is at stake from an educational perspective remains the integration of what we may learn from reflecting on crises - whether past, present, or anticipated - into the "normalcy" of the everyday life. Based on the contribution developed in this paper, increasing one's capacity to make purposeful life choices may rely on how people develop the ability to individually and collectively regulate and critically reflect on the rhythms through which transformational processes shape and constrain their lives. Insofar as it immediately refers to a critical tension between order and movement, substance and flow, the concept of rhythm appears indeed critical to consider the fluidity of the everyday life and the lifespan more broadly (Alhadeff-Jones, 2017; Bachelard, 1950; Pineau, 2000). Such an approach requires the elaboration of a theory of crises, as much as it may require the development of a "rhythmic intelligence" (Alhadeff-Jones, 2021a) based on the capacity, individual and collective, to know, understand and represent the rhuthmoi (Michon, 2005), that is, the moving forms or ways of flowing, inherent to any organized, observed, experienced or disputed phenomenon. The contribution made in this paper may therefore appear as a starting point for broader inquiry, going beyond complexity theories, and relating among others to current scientific developments around rhythm theories and rhythmanalysis (e.g., Michon, 2005, 2021; Sauvanet, 2000). Exploring such resources in education (e.g., Alhadeff-Jones, 2017; 2018, 2019a, 2019b, 2020, 2021b) may constitute a strategic move to develop further theoretical, methodological, and practical contributions, focusing on the continuous and discontinuous aspects of adult life and lifelong education.

\section{References}

Alhadeff-Jones, M. (2017). Time and the rhythms of emancipatory education. Rethinking the temporal complexity of self and society. London: Routledge. https://doi.org/10.4324/9781315727899

Alhadeff-Jones, M. (2018). Pour une approche rythmologique de la formation. Education Permanente, 217, 21-32.

Alhadeff-Jones, M. (2019a). Time and the rhythms of transformative learning. In T. Flemming, A. Kokkos, \& F. Finnegan (Eds.), European perspectives on transformation theory (pp. 93-109). Basing Stock, UK: Palsgrave-Macmillan.

Alhadeff-Jones, M. (2019b). Beyond space and time: Conceiving the rhythmic configurations of adult education through Lefebvre's rhythmanalysis. Zeitschrift für Weiterbildungsforschung, https://doi.org/10.1007/s40955-019-0133-0

Alhadeff-Jones, M. (2020). Explorer l'inconscient rythmique dans les pratiques d'histoire de vie en formation. Education Permanente, 222, 43-51.

Alhadeff-Jones, M. (2021a, February). Rhythmic intelligence as a specific form of intelligence. Rhythmic Intelligence. http://www.rhythmicintelligence.org/blog/2021/2/22/rhythmic-intelligence-definition

Alhadeff-Jones, M. (2021b). Time and the rhythms of academia: A rhythmanalytical perspective. In F. Vostal (Ed.), Inquiring into academic timescapes (pp. 21-37). Bingley, UK: Emerald Publ.

Alhadeff-Jones, M., \& Kokkos, A., (Eds.). (2011). Transformative Learning in Time of Crisis: Individual and Collective Challenges. Proceedings of the 9th International Transformative Learning Conference. New York \& Athens, Greece: Teachers College, Columbia University \& The Hellenic Open University.

Alheit, P., Bron-Wojciechowska, A., Brugger, E., \& Dominicé, P. (Eds.). (1995). The biographical approach in European adult education. Vienna: Verband Wiener Volksbildung.

Argyris, C., \& Schön, D.A. (1978). Organizational learning: A theory of action perspective. Reading, MA: Addison-Wesley.

Bachelard, G. (1950). La dialectique de la durée. Paris: PUF.

Barus-Michel, J., Giust-Desprairies, F., \& Ridel, L. (1996). Crises. Approche psychosociale clinique. Paris: Desclée de Brouwer. 
Bateson, G. (1973). Steps to an ecology of mind. London: Paladin, Granada.

Baudouin, J. M. (2014). La phrase qui tue. La notion d'épreuve, de la dissémination à la conceptualisation. In J. Friedrich, \& J. C. Pita Castro (Eds.), La recherche en formation des adultes: un dialogue entre concept et réalité (pp. 223-251). Dijon, France: Raison \& Passions.

Béjin, A., \& Morin, E. (Eds.). (1976). La notion de crise. Communications, 25.

Boutinet, J.-P. (1998). Psychologie de la vie adulte. Paris: PUF.

Delory-Momberger, C. (2003). Biographie et éducation: Figures de l'individu-projet. Paris: Anthropos.

Dominicé, P. (2000). Learning from our Lives. Using Educational Biographies with Adults. San Francisco: Jossey-Bass.

Galvani, P. (2019). Autoformation et connaissance de soi. Lyon: Chronique Sociale.

Jullien, F. (2011). The silent transformations (K. Fijałkowski \& M. Richardson, Trans.). Chicago, IL: Seagull Press.

Kaës, R. (Ed.). (1979). Crise, rupture et dépassement. Paris: Dunod.

Kjaer, P. F., \& Olsen, N. (2016). Critical Theories of Crises in Europe: From Weimar to the Euro. London: Rowman \& Littlefield International.

Koselleck, R., \& Richter, M. W. (2006). Crisis. Journal of the History of Ideas, 67(2), 357-400.

Lesourd, F. (2009). L'homme en transition: Éducation et tournants de vie. Paris : Economica-Anthropos.

Mezirow, J. (1991). Transformative Dimensions of Adult Learning. San Francisco: Jossey-Bass.

Michon, P. (2005). Rythmes, pouvoir, mondialisation. Paris: PUF.

Michon (2021). Elements of rhythmology (4 vol.). Paris: Rhuthmos.

Morin, E. (1976). Pour une crisologie. Communications, 25(1), 149-163.

Morin, E. (2008). La Méthode. Paris: Seuil.

Nohl, A.-M. (2015). Typical phases of transformative learning: A practice-based model. Adult Education Quarterly, 65(1), 35-49.

Pineau, G. (2000). Temporalités en formation. Vers de nouveaux synchroniseurs. Paris: Anthropos.

Rescher, N. (2000). Process Philosophy. A survey of Basic Issues. Pittsburgh, University's[e-iof Pittsburgh Press.

Roux-Dufort, C. (2000). La gestion de crise. Un enjeu stratégique pour les organisations. Paris: DeBoeck.

Sauvanet, P. (2000). Le rythme et la raison (2 vol.) Paris: Kimé.

Tosey, P., Visser, M., \& Saunders, M. N. K. (2012). The origins and conceptualizations of 'tripleloop'learning : A critical review. Management learning, 43(3), 291-307.

West, L., Alheit, P., Andersen, A.S., \& Merrill, B. (Eds.). (2007). Using biographical and life history approaches in the study of adult and lifelong learning: European perspective. Frankfurt: Peter Lang. 